NASA Technical Memorandum 87280

AIAA-86-1513

1265

\title{
Structural Integrity and Durability for Space Shuttle Main Engine and Future Reusable Space Propulsion Systems
}

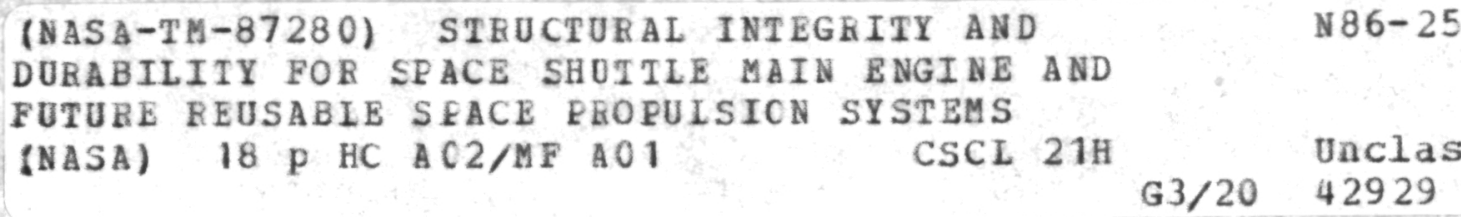

Stanley J. Marsik

Lewis Research Center

Cleveland, Ohio

and

Henry T. Gawrylowicz

Headquarters

Washington, D.C.

Prepared for the

22nd Joint Propulsion Conference

cosponsored by the AIAA, ASME, SAE, and ASEE

Huntsville, Alabama, June 16-18, 1986

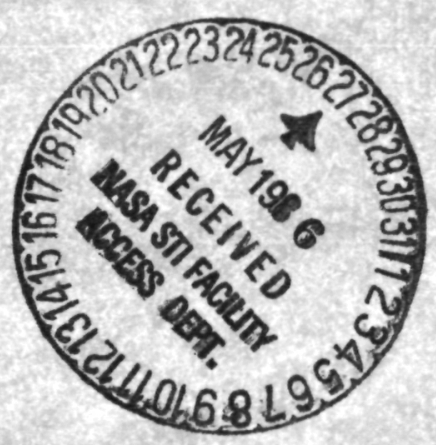




\title{
STRUCTURAL INTEGRITY AND DURABILITY FOR SPACE SHUTILE MAIN ENGINE
}

AND FUTURE REUSABLE SPACE PROPULSION SYSTEMS

\author{
Stanley J. Marsik \\ National Aeronautics and Space Administration \\ Lewis Research Center \\ cleveland, ohio
}

and

Henry T. Gawry lowicz*

National Aeronautics and Space Administration

Headquarters

Washington, D.C.

\section{SUMMARY}

The space shuttle main engine (SSME), a reusable space propulsion system, is the most sophisticated earth-to-orbit propulsion system in use today. Based on the premise that the United States will depend on the Shuttle and its derivative versions for space transportation for the next several decades, NASA is conducting a program which will establish a technology base for the orderly evolution of reusable space propulsion systems. As part of that program, NASA has initiated a Structural Integrity and Durability effort for advanced highpressure oxygen-hydrogen rocket engine technology. That effort described in this paper, focuses on the development of: (1) accurate analytical models to describe flow fields, aerothermodynamic loads, structural responses, and fatigue/fracture, from which life prediction codes can be evolved, and (2) advanced instrumentation with capabilities to verify the codes in an SSME-like environment as well as the potential for future use as diagnostic sensors for real-time condition monitoring of critical engine components. The work is conducted through in-house activities at NASA Lewis, industrial contracts and university grants. This paper high-lights the most recent technical accomplishments.

\section{INTRODUCTION}

The current and planned U.S. space program relies on the reusability and high performance of the space propulsion systems. High performance of the current system, the space shuttle main engine (SSME), is attained by the use of a staged combustion power cycle coupled with high combustion chamber pressure. Referring to the SSME power head components (fig. 1), the propellants are partially burned at a low mixture ratio, high pressure and relatively low temperature in the preburner to produce hydrogen-rich gas (steam) which powers the high performance turbopumps. The hydrogen-rich gas is then directed to the main injector, where it is injected along with additional oxygen, into the main combustion chamber at high mixture ratio ( $6: 1$ oxidizer to fuel). Flows, temperatures and pressures for the engine operating at full power are shown in figure 2.

\footnotetext{
*Associate Fellow, AIAA.
} 
The United States will depend on the shuttle and its derivative versions as its principal Earth-to-Orbit transportation system for the next several decades. Therefore, NASA has decided to establish a technology base for the orderly evolution of advanced high pressure oxygen-hydrogen engines. This research and technology program is described in reference 1. A large portion of this program is devoted to the structural integrity and durability aspect of reusable space propulsion systems.

This effort is sponsored by the SSME Program office and focuses on the development of analytical tools which will enable more reliable life predictions of components/subsystems and lead to improved performance and operations of reusable space propulsion systems. It includes advanced materials and processes development and evaluation, life prediction models and establishment of probability density functions for material fatigue life.

\section{STRUCTURAL INTEGRITY AND DURABILITY EFFORT}

Long life, safety and durability requirements along with high performance requirements for reusable space propulsion systems call for availability of analytical tools which will accurately calculate usable mission lifetime. These systems must survive in a fatigue environment consisting of complex mechanical and thermal loading spectra. The analytical methods and predictive tools presently available are highly empirical in nature and with few exceptions have not been developed or verified specifically for space propulsion systems, but rather derived from the body of technology developed for applications such as aircraft turbomachinery.

NASA Lewis has been conducting an effort since the latter part of 1983, whose objective is to develop the necessary analytical tools for reliable life prediction of critical life-limiting components of a space propulsion system. This effort, commonly referred to as the Durability effort, focuses on the operating environment (i.e., extreme hot-gas dynamic/thermal/mechanical conditions), composite loading, fatigue and fracture analysis of the hot section of a rocket engine.

It is the unique aspects of the SSME, i.e., aggressive environment (type of fuel and oxidizer, as well as operating pressure), very high thermal and mechanical loads (in the inelastic regime of currently used materials), and relatively short lives (under 100 mission cycles), that make it necessary to develop and demonstrate extensions to the existing analytical models, thereby reducing the risk associated with "conventional" approaches to analysis and life predictions of such systems. The Durability effort is being pursued in four major disciplines:

(a) Aerothermodynamic loads definition

(b) Structural responses

(c) Fatigue/fracture and constitutive modeling

(d) Instrumentation development to verify (a) to (c).

The effort is strongly supported by the development of advanced materials and materials processes. The results of the disciplinary approaches will be integrated in the development of a life predicting method for the critical 
components or subsystems of the engine. Several typical concerns of the effort and the approach to the development of life prediction are indicated in figures 3 and 4 .

The focus of the Durability effort is to develop analytical methods in areas with generic technology deficiencies. This type of research is generally evolutionary. Therefore, expected benefits will be in the long-term, rather than resolutions to current specific programs. However, short-term benefits are expected to surface during the development of the analytical methods. These benefits could have an impact in:

(a) engine environment definition

(b) time-phasing of loads

(c) stress/strain prediction

(d) guidelines for design modifications to enhance service life

Research in the Durability effort is conducted through industrial contracts, university grants, and in-house activities at NASA Lewis.

\section{Aerothermodynamic Loads Definition}

The objective of this effort is to develop models to describe and statistically simulate hot-gas-dynamic flow, including thermal, mechanical, and environmental conditions in the SSME. The areas of investigation include the preburner region, the turbine, the turnaround duct, the hot gas manifold, and the injector post region. Development of steady-state and time dependent three-dimensional viscous computer codes, including their experimental verification are considered to be essential to achieving that objective. The steady and transient operating loads must all be well defined in order to accurately predict power-head life. Early efforts in aerothermal loads have been focusing on:

(a) computation of the fuel turbine losses

(b) turbine inlet temperature profiling

(c) viscous computations of the first stage rotor profile

(d) flow analysis in the turnaround duct

(e) steady and unsteady flows in multistage turbines

(f) experimental measurements and analysis of heat transfer and gas dynamics

(g) flow-induced vibration in the main injector liquid oxygen (LOX) posts area

Results for these tasks are discussed in detail in Refs. 2 and 3. Two examples are briefly

described below.

FLOW ANALYSIS OF THE SSME TURNAROUND DURC (TAD)

The SSME fuel turbopump hot gas manifold (HGM) has been identified as a source of pressure loss and flow distortion which significantly affects the performance and durability of both the drive turbine and the Lox injector area of the main combustion chamber. The TAD is the axisymmetric part of the manifold at the exit of the turbine. Flow separation in the TAD which carries 
approximately 75 percent of the fuel to the main injector could create a pressure drop in the region. Such a pressure drop may have to be compensated for by increased turbine inlet temperature. In addition, flow separation creates disturbances which may propagate into the main injector LOX posts region, thereby contributing to injector post failure.

The region of investigation and the results of the analysis are shown in figure 5. An axisymmetric/turbulent viscous computation was performed using the NASA Lewis Axisymmetric Diffuser Duct (ADD) computer code. The computation was based on the turbine exhaust conditions and indicates three areas of potential separation. The study of the geometric effects has shown that by optimizing wall curvature and flow diffusion in the turnaround, improved TAD performance can be achieved. The details of the study can be obtained from reference 4.

SSME FUEL AND OXIDIZER TURBINE LOSS ANALYSIS

Aerodynamic losses in either high pressure turbine of the SSME have to be compensated for by increasing the turbine inlet temperature in order to achieve the required power. Increased turbine inlet temperatures result in reduced life and durability of the engine. Assessment of these aerodynamic losses in both the high-pressure fuel turbine (HPFT) and high-pressure oxidizer turbine (HPOI) were made at the full power level (FPL) condition, i.e., 109 percent of the rated power level (RPL), using a quasi-three-dimensional flow and boundary layer analysis method. The results were used to calculate blade and end-wall friction losses and trailing-edge mixing losses. Additional empirical correlations were used to calculate losses due to rotor tip clearance, incidence, secondary flow, and rotor blade surface roughness. The calculations were performed at Reynolds numbers equal to those in the engines.

The region of analysis and the results for the two turbines are shown in figures 6 and 7 . The HPF 1 had a calculated overall two-stage efficiency of 85.2 percent. A 5-point efficiency loss was attributed to roughness of the rotor blade surface due to the nickel-chromium-aluminum yttria (NiCrAlY) bond coating that had been plasma sprayed on the blade. The surface roughness was measured as 250 uin rms (ref. 5). The rotor tip clearance loss was the next most significant loss for the HPFT, accounting for 4 points. The HPOT had a calculated overall two-stage efficiency of 80.1 percent. An eight-point efficiency loss was attributed to rotor incidence and a 6.3 point loss to pro file and mixing effects. The results indicate that the HPFl losses could be reduced by modifying the existing blading to improve the surface finish, whereas a reduction in losses in the HPOI would require redesign of the blad. ing. The details of the calculation procedure can be obtained from reference 6 .

\section{Structural Response}

Material thermomechanical behavior is difficult to characterize in the SSME service environment. The complex loading conditions are characterized by static and centrifugal load envelopes; structural, dynamic, acoustic, and impulsive excitations; extreme temperature excursions; and gas pressure fluctuations. 
Moreover, the nondeterministic load conditions, anisotropic material behavior, large cyclic and transient strains, nonlinear thermomechanical transients and material degradation require advanced analytical methods (e.g., probabilistic structural analysis) to accurately predict the structural response in such a severe service environment. Advanced three-dimensional analysis methods need to be formulated to accommodate the limited deterministic and probabilistic complex loading spectra as well as the anisotropic behavior of the material. Such analyses are not presently available and a recourse is made to incremental, iterative methods available in general-purpose structural analysis programs.

\section{DEVELOPMENT OF PROBABILISTIC STRUCTURAL ANALYSIS METHODS}

Currently available methodology for deterministic, three-dimensional, inelastic analysis is being augmented to accommodate the complex probabilistic loading spectra, the thermoviscoplastic material behavior, and the material degradation associated with the environment of space propulsion systems. The development of probabilistic structural analysis methodology consists of the following major work elements:

(a) composite load spectra

(b) probabilistic structural analysis methods

(c) probabilistic finite element theory - new variational principles

(d) probabilistic structural analysis application.

An example of an application of probabilistic methods to structural analysis of SSME type components, such as high pressure turbopumps (HPTP) turbine blade, is indicated in figure 8 . These methods are expected to evaluate the geometric variations and material properties (e.g., natural frequencies), their tolerances as well as probability of exceedance, for nondeterministic load conditions. The results are expected to provide an understanding of the level and degree of safety inherent in a deterministic design.

Progress by various participants in this effort (i.e., contractors, grantees, NASA Lewis) can be obtained from reference 3. An early version of a structural analysis computer code based on probabilistic finite element is now available at NASA Lewis.

\section{Fatigue, Fracture and Constitutive Modeling}

The design of reusable space propulsion systems will unavoidably contain components with relatively short lives. It is necessary to understand the characteristics of the life-limiting components before the design is committed to hardware. Also, knowledge of possible design tradeoffs and their quantitative assessment will result in adjustment of design parameters such as perform. ance, weight and size, to maximize the useful cyclic lifetime of the system.

The objective of the NASA Lewis Fatigue, Fracture, and Constitutive Model ing effort is to develop and verify cyclic constitutive stress-strain and life. prediction models for materials used in reusable space propulsion systems.

The life prediction models are aimed at accurately calculating the initiation and early growth resistance of cyclic cracks in materials used in hot-gas-path 
components, taking into account phenomenological variables and the micromechanistic features of the materials. To meet the objective, it will be possible to utilize the technology base developed in support of the aeronautics gasturbine industry. However, because of the exceptionally rigorous demands of rocket engine systems, the life prediction and cyclic constitutive material models developed for air-breathing engines must be reassessed for applicability to reusable space propulsion systems. Crack initiation approaches are being addressed from a theoretical as well as experimental point of view.

Developed models will be subjected to verification at the subcomponent level to demonstrate their applicability to the unique conditions of reusable space propulsion hardware.

\section{RE-EXAMINATION OF CUMULATIVE FATIGUE DAMAGE LAWS}

Treatment of accumulated fatigue damage in materials and structures subjected to a history of complex repetitive loadings has been receiving consider. able attention in recent years. It has been recognized for some time that application of Miner's "classical" Linear Damage Rule (LDR) results in life predictions which are too optimistic for material/structural behavior in reusable space propulsion systems. Over the years, a number of alternative nonlinear methods have been proposed for more accurate predictions. However, most of these techniques required evaluation of material constants from extensive cumulative fatigue damage tests. A notable exception among the modifications is the so called Damage Curve Approach (DCA) and its bi-linear equivalent, the Double Linear Damage Rule (DLDR), developed at NASA Lewis and introduced in 1980 .

The Damage Curve Approach (DCA) and the Double Linear Damage Rule (DLDR) for cumulative fatigue damage analysis of materials and structures have now been re-examined and modified to improve their accuracy and applicability to engineering problems associated with reusable space propulsion systems. The advantageous features of each were incorporated into what is known as the Double Damage Curve Approach (DDCA). The newly developed DDCA utilizes the two universalized constants from the DCA and DLDR formulations. Thus, no new information is required to perform a cumulative damage fatigue life prediction. However, if specific cumulative damage data are available, they can be incorporated by optimizing the two constants in the DDCA equation. Successfully applied DDCA, using specific material constants, to recently obtained low cycle fatigue (LCF)/high-cycle fatigue (HCF) interaction experimental results for the alloy Haynes 188 , can be seen in figure 9 . Haynes 188 is the material used for the SSME LOX Posts in the Main Injector Assembly. The experimental data for the alloy were obtained at NASA Lewis, at $1400^{\circ} \mathrm{F}$. It can be seen that entering the lower bound curve in the figure at a LCF damage of 0.10 , i.e., only 10 percent of the expected LCF life, one could expect to use only 0.04 of HCF damage before failure would occur. That is, only 4 percent of the normal HCF life. This is in sharp contrast to a value of 90 percent HCF life that the LOR would have erroneously predicted.

The detailed discussion of the cumulative fatigue damage laws re-examination and the DDCA application can be obtained from references 7 and 8. 


\section{Instrumentation}

Strong emphasis in the SSME durability program is placed on the development of analytical codes for designing components and predicting their expected life. The codes will have to be verified in a series of benchmark experiments specifically designed and instrumented for correct operating conditions.

The instrumentation portion of the Durability program is aimed at the development of sensors and instrumentation systems capable of providing reliable data for computer codes verification. The verification of the codes requires steady state and transient measurements of: (1) flow and flow profile, (2) gas temperatures, (3) heat fluxes, (4) engine components surface temperatures, and (5) engine components surface strains. Typical measurement locations are: (a) turbine blades and vanes, (b) transfer ducts (turnaround and hot gas manifold), (c) main injector (LOX posts region), and (d) main combustion chamber. The computer codes developed in the Durability effort will work with relatively high resolution maps of flow, strain and temperature parameters. Therefore, the instrumentation system must also produce data that are very high in both spatial and temporal resolution.

As is true for the durability disciplines, the instrumentation effort is also based on advanced technology originally developed for aeropropulsion. That technology is being expanded to include the operating conditions and materials of the SSME. The development is focused on four areas:

(a) thin film sensors for temperature, strain, and heat flux measurements,

(b) optical flow measurement systems,

(c) optical surface strain mapping systems,

(d) gas temperature probes with a frequency response in a $\mathrm{kHz}$ range.

A brief discussion of two work elements in the thin film sensor area follows.

\section{THIN FILM SENSORS FOR SPACE PROPULSION TECHNOLOGY}

SSME components such as the turbine blade of the high-pressure fuel turbopump are subjected to rapid and extreme thermal transients. The durability models will encompass the start-up and shut-down transients. However, validation of these models will depend on reliable sensors with the capability of providing direct measurements of the environment.

Through a previous effort, thin-film temperature sensor technology was developed at NASA Lewis. Sputter-deposited thermocouple junctions with their lead wires formed by hot-compression diffusion bonding performed successfully in engine tests at or up to $1800^{\circ} \mathrm{F}$ for more than $60 \mathrm{hr}$ with less than 0.02 percent drift/hr. This technology base is being expanded to apply to the SSME conditions primarily in the area of material compatibility. The details of this effort and the current status can be obtained from reference 9 . The thin-film technology developed for temperature sensors will be extended to other sensors such as those for strain measurement. 


\section{HEAT FLUX SENSOR CONDITIONS}

The heat flux to SSME turbopump turbine blades may be as high as $10^{7} \mathrm{~W} / \mathrm{m}^{2} .10$ Such a heat $\mathrm{flux}$ is 50 to 100 times that encountered in aircraft engines. New technology is needed for the development of heat flux sensors with such a capacity. Moreover, a new system capable of calibrating these sensors must be developed since no such facility exists.

A calibrator under development at NASA Lewis for this purpose uses an arc lamp developed from NASA Lewis electrode technology. The lamp with power to $300 \mathrm{~kW}$ (fig. 10), is now commercially available. Adjustable irradiance can be focused on the entire area of a pressure or suction surface of an SSME turbine blade at levels to $10^{7} \mathrm{~W} / \mathrm{m}^{2}$ with a uniformity of 1 to 2 percent. The lamp will be remotely operated in either a pulsed or steady-state mode and is reported to have a lamp life of several hundred hours. Details concerning heat flux calibrator development can be obtained from reference 10.

\section{Advanced Materials and Processing}

Advanced high pressure oxygen-hydrogen propulsion systems create a very challenging operating environment for materials. For example, the high pres sure turbopumps turbine materials are subjected to thermal transients unprecedented in man-rated reusable turbomachinery. Other components operate in either hydrogen or hydrogen-steam environments which severely tax the performance of common alloys. A broader and/or new material data base is needed to satisfy the requirements of this class of propulsion system.

A variety of advanced materials were included in a study to identify those with the potential to alleviate the durability problem. Six classes of candidate materials were evaluated for turbine blade life enhancement and/or evolutionary performance enhancement of the SSME hot section (ref. 11). The material classes evaluated were: (a) single crystal and advanced single crystal alloys; (b) directionally solidified eutectic superalloys; (c) oxide dispersion-strengthened superalloys; (d) rapid solidification processed superalloys; (e) fiber reinforced superalloy composites; and (f) structural ceramics.

The study focused on the three key material properties indicative of the operational life for an SSME turbine blade: (1) stress-rupture strength; (2) mean stress high-cycle; and (3) thermal strain low-cycle fatigue strength. It identified advanced single crystal alloys (ASC), i.e., high thermal gradient directionally solidified or post solidification hot isostatic pressing of con. ventionally processed single crystal alloy, as a class of materials which would enhance the SSME turbine blade durability by tenfold with the current turbine design (i.e., retrofit) and current operating conditions. The study also identified fiber reinforced superalloys (FRS) as a blade material which could produce higher engine performance by allowing the turbine to operate at a $400^{\circ} \mathrm{F}$ increased temperature, while still providing an increase in durability of approximately twentyfold. However, the use of FRS materials would require a modification in the design of the turbine wheel to accommodate the blade mounting. While structural ceramic materials were also found to offer a high payoff at increased temperatures, they are not expected to be available for rocket engine applications before 1995. 
The life enhancement and the performance enhancement can be seen from figure 11. In the figure a comparison is made between the advanced materials (ASC and FRS) for rocket engine turbine blades and the currently used materials in the SSME - MAR M246. Life enhancement for each of a minimum of 30 launches could be expected. Moreover, the blades fabricated from FRS materials can operate at $400^{\circ} \mathrm{F}$ higher turbine inlet temperature, thereby providing the capability for increased turbine performance in addition to the increased durability. The details of the study can be obtained from reference 11 . The development of both advanced materials for use in reusable space propulsion systems is in progress.

\section{TUNGSTEN-REINFORCED COPPER THRUST CHAMBER LINER}

The inner wall liner of reusable rocket thrust chambers operating at high chamber pressures are fabricated from materials of high thermal conductivity and high strength.

Current liners are fabricated from high strength copper alloys capable of transmitting the high heat load from the hot-gas-side wall to the coolant and of carrying the high pressure load. The liner of the SSME, for example, is fabricated from NARloy $Z$, which contains 96 percent copper and has 93 percent of the thermal conductivity of oxygen-free, high conductivity copper (ref. 5 ). However, the severe environment irreversibly deforms and thins the cooling passage wall during each firing cycle. Repeated cycles cause cracks in the wall and eventual failure of the thrust chamber. Using a composite material made up of tungsten wire in a copper matrix offers the potential for extending thrust chamber life. The tungsten has the high strength necessary to carry the pressure loads and prevent deformation of the cooling passage wall, and the copper has the high conductivity necessary to transmit the heat load to the coolant. Laboratory data (fig. 12) shows that the copper-tungsten com. posite, with only 10 percent volume of tungsten, has a rupture strength 80 percent higher than NARloy- $Z$ with a thermal conductivity reduction of only 5 percent. Fabrication feasibility has been demonstrated at NASA Lewis for both cylindrical and contoured rocket thrust chamber liners. The details of the fabrication process can be obtained from reference 12. Preparations for hot-fire testing of a tungsten-reinforced copper thrust chamber liner at NASA Lewis are in progress.

\section{SUMMARY}

The Structural Integrity and Durability of Reusable Space Propulsion Systems research effort was instituted by NASA to establish basic discipline technology and develop generic analytical tools which would provide basis for improved designs of future reusable space propulsion systems, with maximum possible technology transfer, in the near term, to the SSME.

The effort consists of three main disciplines which focus on analysis of the hot-gas-section of a rocket engine. The three disciplines: aerothermodynamic loads; structural responses; and fatigue, fracture and life prediction, are receiving a strong support from an effort in advanced instrumentation techniques for verification of the analytical models and from the development of advanced materials and material processes. 


\section{REFERENCES}

1. Marsik, S.J., and Morea, S.F., "Advanced Research and Technology Program for Advanced High-Pressure Oxygen-Hydrogen Rocket Propulsion," NASA TM-86969, 1985.

2. Advanced High Pressure $\mathrm{O}_{2} / \mathrm{H}_{2}$ Technology, NASA CP-2372, S.F. Morea and S.T. Wu, eds., 1984.

3. Structural Integrity and Durability of Reusable Space Propulsion Systems, NASA CP-2381, 1985.

4. McLallin, K.L., "Analytical Study of Flow Phenomena in SSME Turnaround Duct Geometrics," Advanced High Pressure $\mathrm{O}_{2} \mathrm{H}_{2}$ Technology, NASA CP-2372, S.F. Morea and S.T. Wu, eds., 1984, pp. 579-598.

5. Research and Technology, Lewis Research Center, Annual Report 1985. NASA TM-87179, 1985.

6. Haas, J.E., "Fuel and Oxidizer Turbine Loss Analysis," Advanced High Pressure $\mathrm{O}_{2} \underline{\mathrm{H}}_{2}$. Technology, NASA CP-2372, S.F. Morea and S.T. Wu, eds., 1984 , pp. $560-570$.

7. Halford, G.R., and Manson, S.S., "Reexamina-tion of Cumulative Fatigue Damage Laws," Structural Integrity and Durability of Reusable Space Propulsion Systems, NASA CP-2381, 1985, pp. 139-145.

8. Bizon, P.T., Thoma, D.J., and Halford, G.R., "Interaction of High-Cycle and Low-Cycle Fatigue of Haynes 188 Alloy at $1400^{\circ} \mathrm{F}$, "Structural Integrity and Durability of Reusable Space Propulsion Systems, NASA CP-2381, 1985, Pp. 129-138.

9. Kim, W.S., and Englund, D.R., "Thin-Film Sensors for Space Propulsion Technology," Structural Integrity and Durability of Reusable Space Propulsion Systems, NASA CP-2381, 1985, pp. 183-188

10. Liebert, C.H., "Heat Flux Sensor Calibrator," Structural Integrity and Durability of Reusable Space Propulsion Systems, NASA CP-2381, 1985, pp. 195-198.

11. Chandler, W.T., "Materials for Advanced Rocket Engine Turbopump Turbine Blades," Rockwell International, Canoga Park, CA, RI/RD83-207, Nov. 1983, (NASA CR-174729). 


\section{ORIGINAL PAGE IS \\ OE POOR QUALITY}

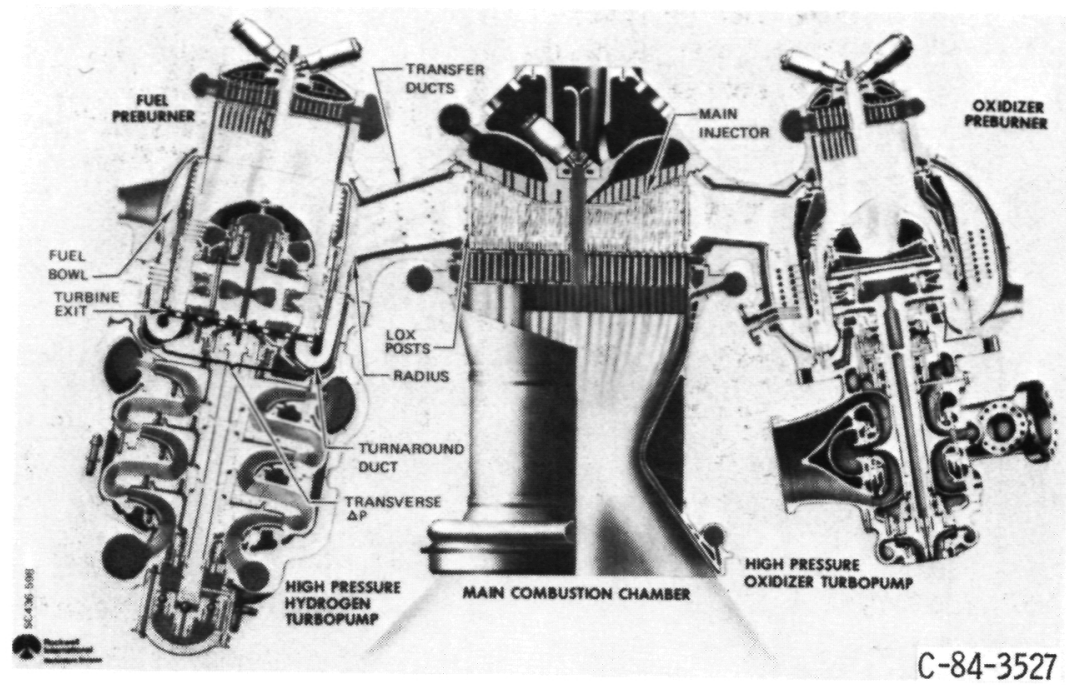

Figure 1. - SSME powerhead component arrangement.

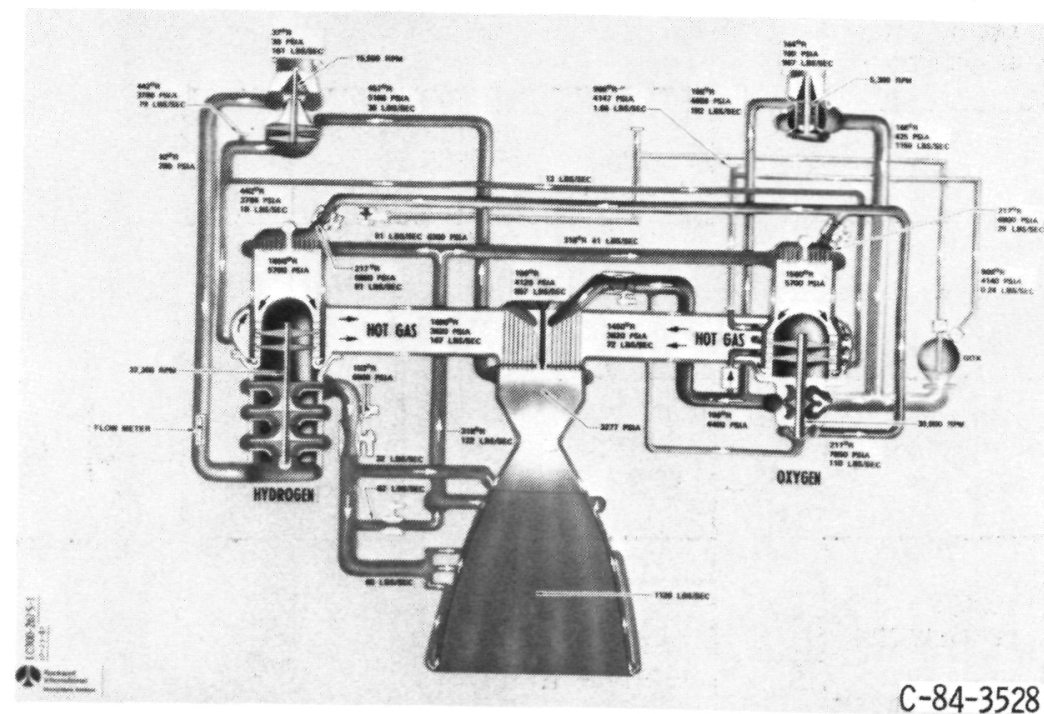

Figure 2. - SSME propellant flow schematic with temperatures and pressures at full power level; MR 6:1. 


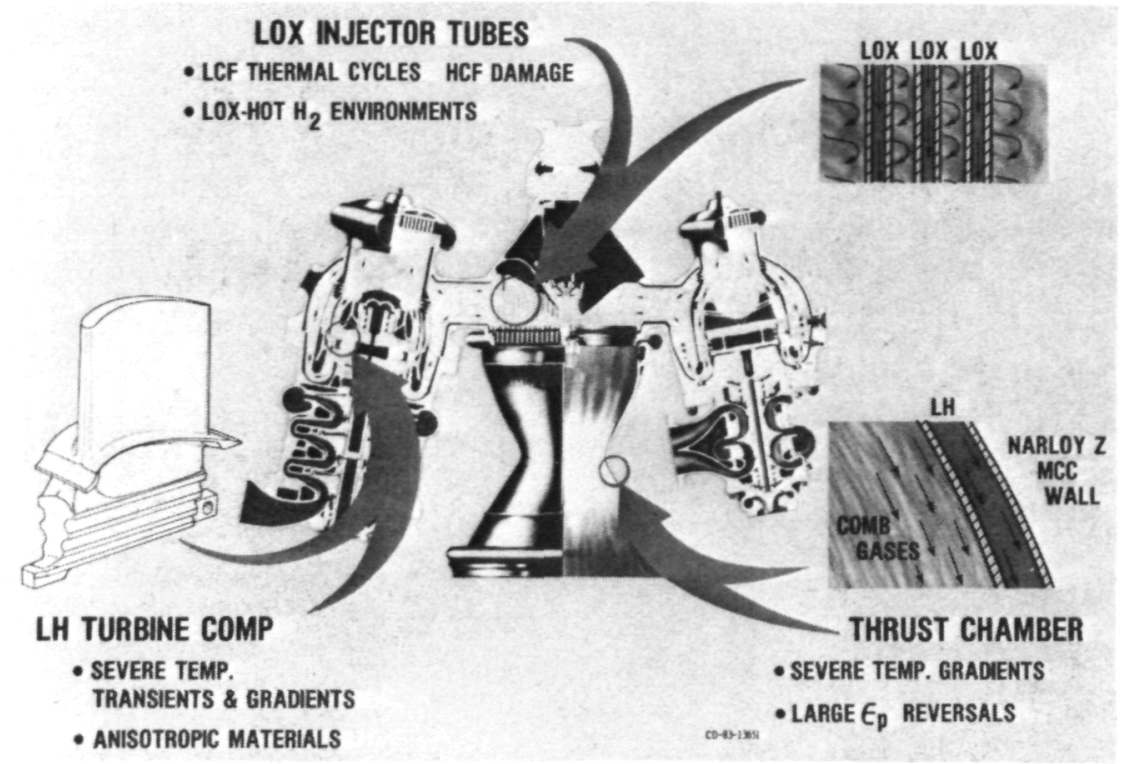

Figure 3. - Typical durability concerns in SSME。

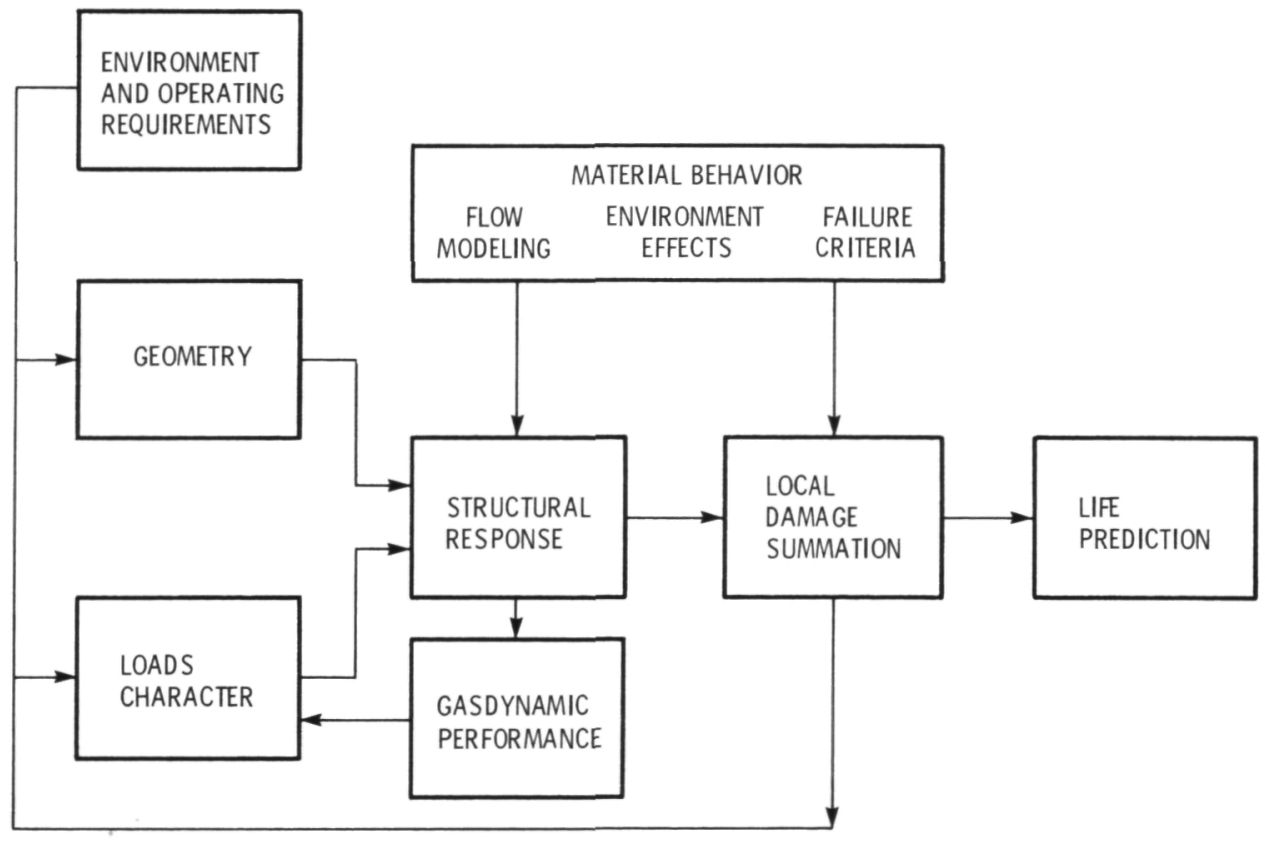

Figure 4. - Life prediction approach. 


\section{ORIGINAL PRG IS \\ OF POOR QUALITY}

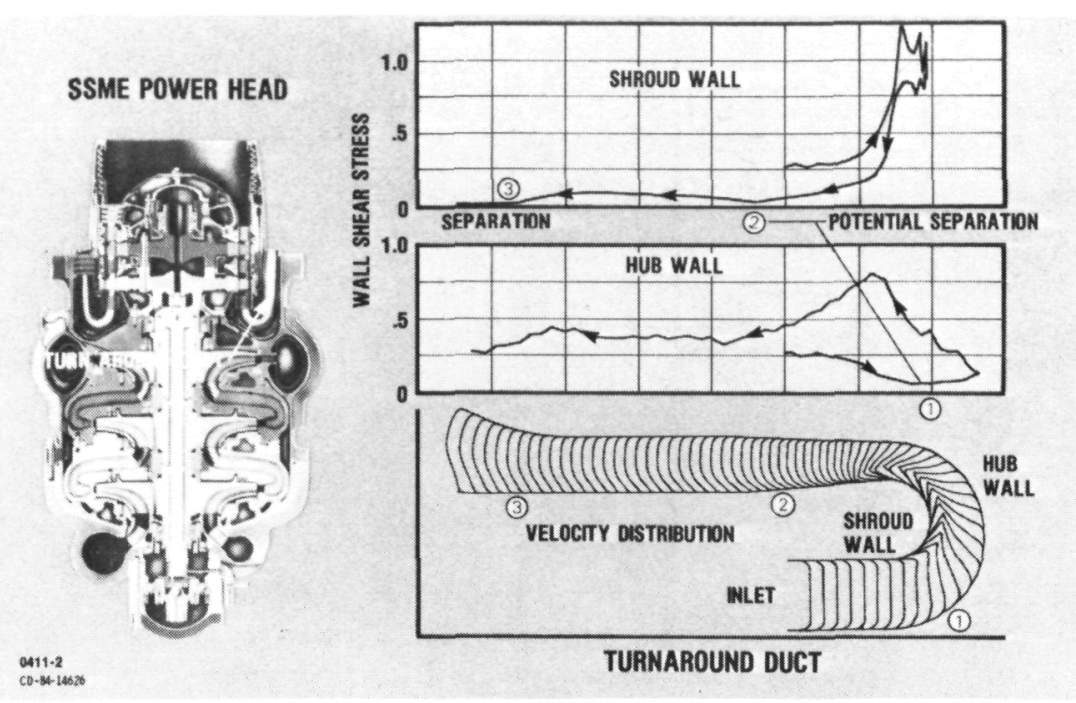

Figure 5. - Flow analysis of the SSME turnaround duct.

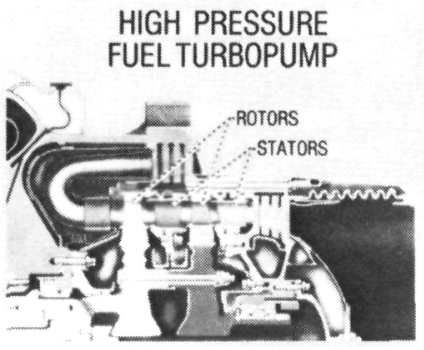

HIGH PRESSURE FUEL. TURBINE LOSSES

$\begin{array}{lc}\text { ROTOR SURFACE ROUGHNESS } & 5.0 \% \\ \text { ROTOR TIP CLEARANCE } & 4.0 \% \\ \text { PROFILE AND MIXING } & 3.0 \% \\ \text { SECONDARY FLOW } & 1.4 \% \\ \text { ROTOR INCIOENCE } & 1.0 \% \\ \text { ENDWALL FRICTION } & 0.9 \% \\ \text { OVERALL EFFICIENCY } & 85.2 \%\end{array}$

IMPROVED SURFACE FINISH CAN IMPROVE EFFICIENCY

Figure 6. - SSME fuel turbine loss analysis.

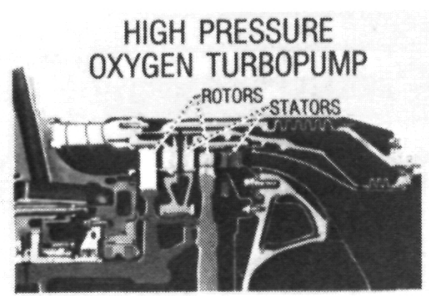

HIGH PRESSURE OXYGEN TURBINE LOSSES

ROTOR INCIDENCE

PROFILE AND MIXING

$8.0 \%$

SECONDABY FLOW

$6.3 \%$

ENDWALL. FRICTION

$3.6 \%$

OVERALL EFFICIENCY

$2.5 \%$

$80.1 \%$

c0.-5.-17)

Figure 7. - SSME oxidizer turbine loss analysis. 


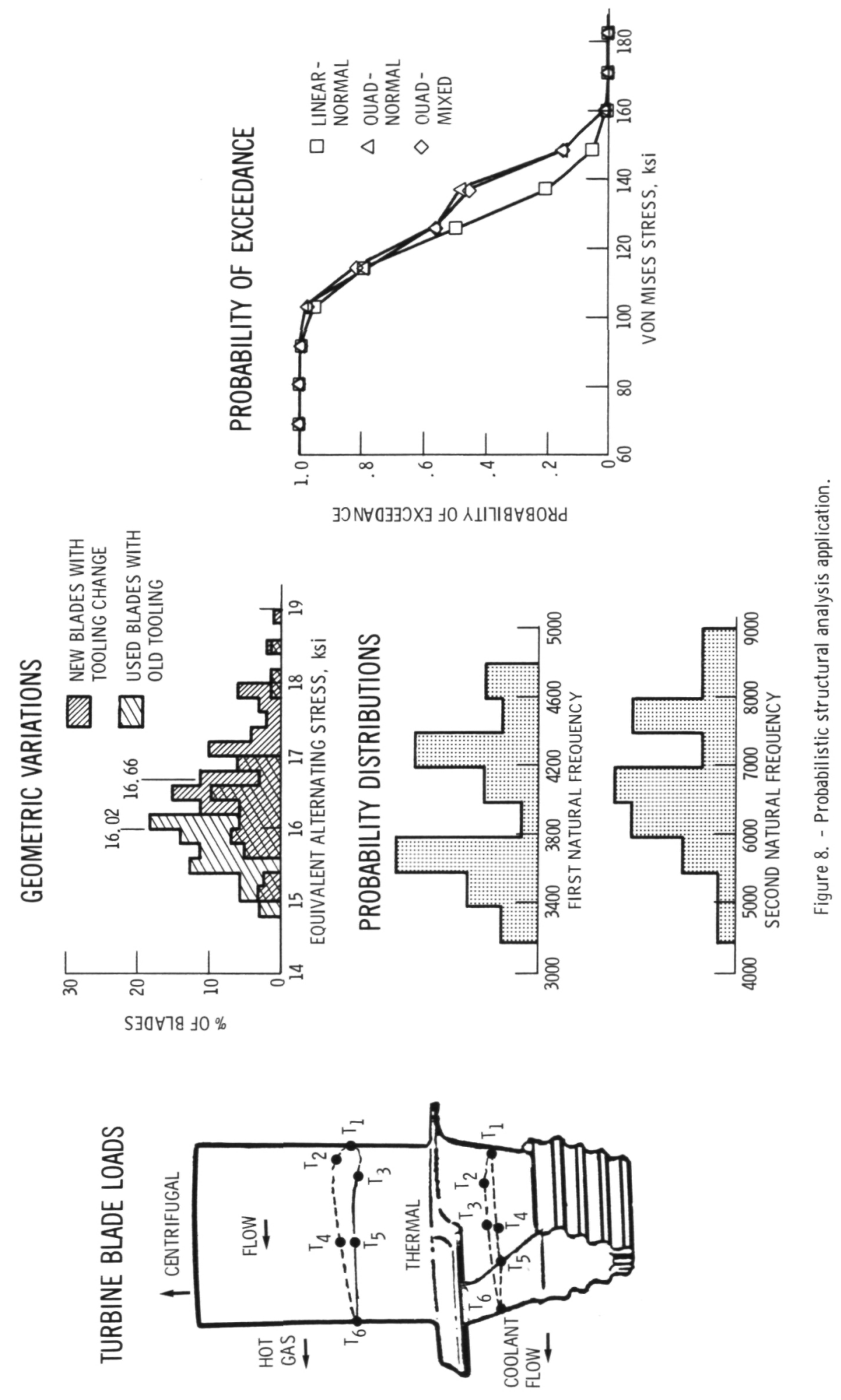


PRIGINAL PAGE 15

ORIGINAL PAGE IS

DF POO 근 OF POOR QUALITY

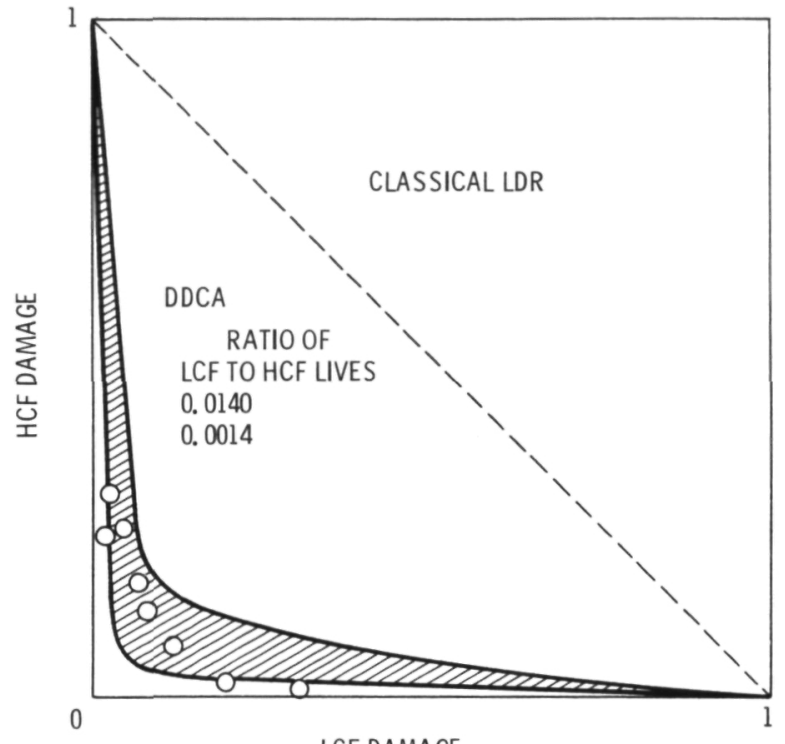

LCF DAMAGE

HAYNES $188,1400^{\circ} \mathrm{F}$

(BIZON, THOMA, HALFORD)

DEFINITIONS

LCF - LOW CYCLE FATIGUE

HCF - HIGH CYCLE FATIGUE

Figure 9. - DDCA applications to Haynes 188.

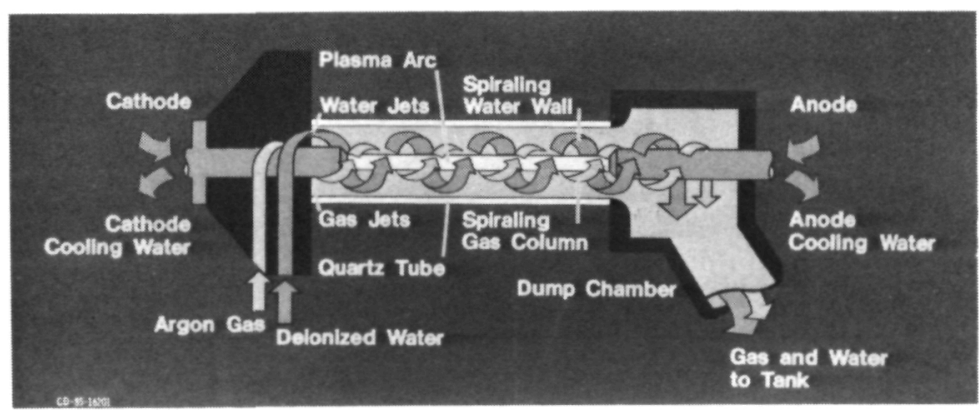

Figure 10.- $300 \mathrm{~kW}$ Vortek arc lamp. 


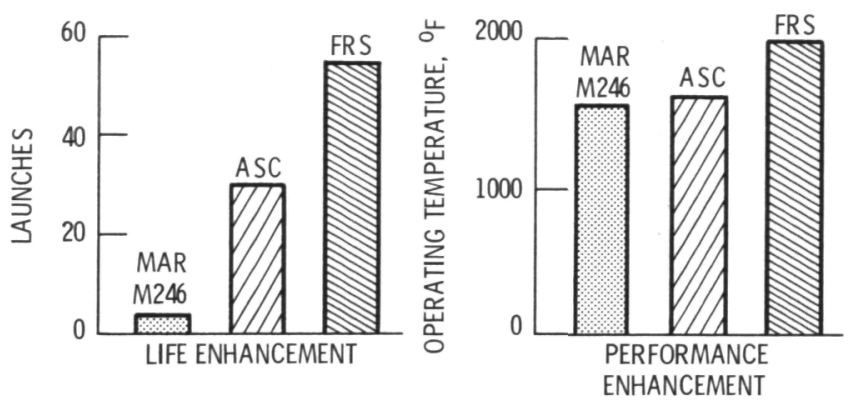

Figure 11. - Advanced materials for rocket engine turbine blades compared to currently used materials in SSME-MAR M246.

PROPERTIES

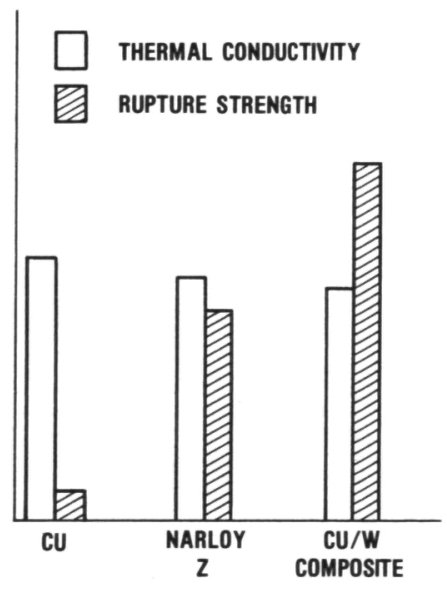

CONSTRUCTION

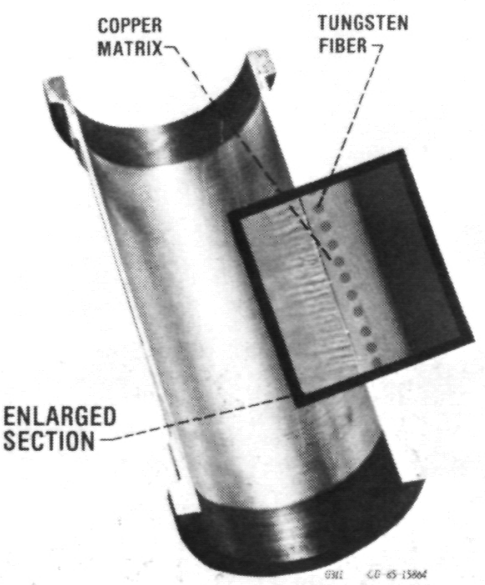

Figure 12. - Tungsten-reinforced copper thrust chamber liner. 


\begin{tabular}{|c|c|c|c|}
\hline \multirow{2}{*}{\multicolumn{2}{|c|}{$\begin{array}{l}\text { 1. Report No. NASA TM-87280 } \\
\qquad \text { AIAA-86-1513 } \\
\text { 4. Title and Subtitle } \\
\text { Structural Integrity and Durability for Space } \\
\text { Shuttle Main Engine and Future Reusable Space } \\
\text { Propulsion Systems }\end{array}$}} & \multicolumn{2}{|c|}{ 3. Recipient's Catalog No. } \\
\hline & & \multicolumn{2}{|c|}{$\begin{array}{l}\text { 6. Performing Organization Code } \\
523-13-00\end{array}$} \\
\hline \multirow{2}{*}{\multicolumn{2}{|c|}{$\begin{array}{l}\text { 7. Author(s) } \\
\text { Stanley J. Marsik and Henry T. Gawrylowicz }\end{array}$}} & \multicolumn{2}{|c|}{$\begin{array}{l}\text { 8. Performing Organization Report No. } \\
\text { E-2983 }\end{array}$} \\
\hline & & \multicolumn{2}{|l|}{ 10. Work Unit No. } \\
\hline \multicolumn{2}{|c|}{$\begin{array}{l}\text { 9. Performing Organization Name and Address } \\
\text { National Aeronautics and Space Administration } \\
\text { Lewis Research Center } \\
\text { Cleveland, Ohio } 44735\end{array}$} & \multicolumn{2}{|c|}{\begin{tabular}{|l|} 
11. Contract or Grant No. \\
13. Type of Report and Period Covered \\
Technical Memorandum
\end{tabular}} \\
\hline \multicolumn{2}{|c|}{$\begin{array}{l}\text { 12. Sponsoring Agency Name and Address } \\
\text { National Aeronautics and Space Administration } \\
\text { Washington, D.C. } 20546\end{array}$} & \multicolumn{2}{|c|}{ 14. Sponsoring Agency Code } \\
\hline \multicolumn{4}{|c|}{$\begin{array}{l}\text { 15. Supplementary Notes } \\
\text { Prepared for the 22nd Joint Propulsion Conference, cosponsored by the AIAA, } \\
\text { ASME, SAE, and ASEE, Huntsville, Alabama, June 16-18, 1986. Stanley J. Marsik, } \\
\text { NASA Lewis Research Center; Henry T. Gawrylowicz, NASA Headquarters. }\end{array}$} \\
\hline \multicolumn{4}{|c|}{$\begin{array}{l}\text { 16. Abstract } \\
\text { The space shuttle main engine (SSME), a reusable space propulsion system, is the } \\
\text { most sophisticated earth-to-orbit propulsion system in use today. Based on the } \\
\text { premise that the United States will depend on the Shuttle and its derivative } \\
\text { versions for space transportation for the next several decades, NASA is conduct- } \\
\text { ing a program which will establish a technology base for the orderly evolution } \\
\text { of reusable space propulsion systems. As part of that program, NASA has initi- } \\
\text { ated a Structural Integrity and Durability effort for advanced high-pressure } \\
\text { oxygen-hydrogen rocket engine technology. That effort described in this paper, } \\
\text { focuses on the development of: (1) accurate analytical models to describe flow } \\
\text { fields, aerothermodynamic loads, structural responses, and fatigue/fracture, from } \\
\text { which iife prediction codes can be evolved, and (2) advanced instrumentation with } \\
\text { capabilities to verify the codes in an SSME-like environment as well as the } \\
\text { potential for future use as diagnostic sensors for real-time condition monitor- } \\
\text { ing of critical engine components. The work is conducted through in house activ- } \\
\text { ities at NASA Lewis, industrial contracts and university grants. This paper } \\
\text { high-lights the most recent technical accomplishments. }\end{array}$} \\
\hline $\begin{array}{l}\text { 17. Key Words (Suggested by Author(s)) } \\
\text { Reusable vehicles } \\
\text { Boosters } \\
\text { Space station }\end{array}$ & $\begin{array}{l}\text { 18. Dist } \\
\text { Un } \\
\text { ST }\end{array}$ & $\begin{array}{l}\text { ent } \\
\text { ry } 20\end{array}$ & \\
\hline $\begin{array}{r}\text { 19. Security Classif. (of this report) } \\
\text { Unc lass if ied }\end{array}$ & $\begin{array}{l}\text { Security Classif. (of this page) } \\
\text { Unc las s if ie }\end{array}$ & 21. No. of pages & 22. Price* \\
\hline
\end{tabular}

*For sale by the National Technical Information Service, Springfield, Virginia 22161 
National Aeronautics and Space Administration

Lewis Research Center

Cleveland. Ohio 44135

Official Business

Penalty for Private Use $\$ 300$
SECOND CLASS MAIL

ADDRESS CORRECTION REQUESTED

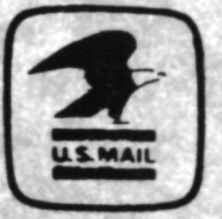

Postage and Fees Paid National Aeronautics and Space Administration NASA-451 